\title{
Equivalent Alkane Carbon Number of Live Crude Oil: A Predictive Model Based on Thermodynamics
}

\author{
Benoit Creton ${ }^{1,2 *}$ and Pascal Mougin ${ }^{1,2}$ \\ ${ }^{1}$ IFP Energies nouvelles, 1-4 avenue de Bois-Préau, 92852 Rueil-Malmaison Cedex - France \\ 2 The EOR Alliance, www.eor-alliance.com \\ e-mail: benoit.creton@ifpen.fr - pascal.mougin@ifpen.fr \\ * Corresponding author
}

\begin{abstract}
We took advantage of recently published works and new experimental data to propose a model for the prediction of the Equivalent Alkane Carbon Number of live crude oil (EACNlo) for EOR processes. The model necessitates the a priori knowledge of reservoir pressure and temperature conditions as well as the initial gas to oil ratio. Additionally, some required volumetric properties for hydrocarbons were predicted using an equation of state. The model has been validated both on our own experimental data and data from the literature. These various case studies cover broad ranges of conditions in terms of API gravity index, gas to oil ratio, reservoir pressure and temperature, and composition of representative gas. The predicted EACNlo values reasonably agree with experimental EACN values, i.e. determined by comparison with salinity scans for a series of $\mathrm{n}$-alkanes from $\mathrm{nC}_{8}$ to $\mathrm{nC}_{18}$. The model has been used to generate high pressure high temperature data, showing competing effects of the gas to oil ratio, pressure and temperature. The proposed model allows to strongly narrow down the spectrum of possibilities in terms of EACNlo values, and thus a more rational use of equipments.
\end{abstract}

Résumé — Développement d'un modèle pour prédire l'alcane équivalent d'une huile vive — En se basant sur de récents travaux de la littérature ainsi que sur de nouvelles données expérimentales, nous proposons un modèle permettant de prédire l'EACNlo (Equivalent Alkane Carbon Number of live crude oil) - alcane équivalent d'une huile vive (pétrole brut contenant des gaz dissous) - dans des contextes de recherche de tensioactifs pour des activités EOR. Pour mettre en œuvre ce modèle, il faut s'assurer de la connaissance des conditions de pression et de température dans le réservoir et du rapport gaz sur huile. En outre, des propriétés volumétriques d'hydrocarbures nécessaires pour alimenter le modèle, sont estimées par l'utilisation d'équations d'état. La validation de notre modèle a été réalisée à partir de données expérimentales de la littérature et nos propres données obtenues pour des pétroles bruts. Ces différents cas d'études couvrent de larges gammes en termes de degrés API, de rapports gaz sur huile, de pressions et températures en condition de fond (réservoir) et de compositions pour le gaz représentatif. L'utilisation du modèle conduit à des valeurs d'EACNlo en accord avec les valeurs expérimentales, i.e. obtenues par comparaisons avec des analyses de salinités sur des séries d'alcanes linéaires de $n \mathrm{C}_{8}$ à $n \mathrm{C}_{18}$. Le modèle a ensuite été utilisé pour générer des prédictions et ainsi étudier l'impact sur les prédictions des conditions de pressions et de températures et de la nature du gaz. Le modèle permet de restreindre la gamme de valeurs d'EACNlo et ainsi une meilleure utilisation des équipements expérimentaux. 


\section{SYMBOLS AND ACRONYMS}

$\alpha \quad$ Coefficient for temperature effect

$\beta \quad$ Coefficient for pressure effect

$\phi \quad$ Number of phases

$\phi \quad$ Volumetric fraction

ABS Branched-chain Alkyl Benzene Sulfonate

ACN Alkane Carbon Number

AES Alkyl Ether Sulfate

AGES Alkyl Glyceryl Ether Sulfonate

AOS $\quad \alpha$-Olefin Sulfonate

API American Petroleum Institute

ASP Alkaline/Surfactant/Polymer

cEOR Chemical Enhanced Oil Recovery

EACN Equivalent Alkane Carbon Number

EACNdo Dead oil EACN

EACNg Gas EACN

EACNlo Live oil EACN

EOR Enhanced Oil Recovery

EoS Equation of State

HLD Hydrophilic Lipophilic Deviation

HP High Pressure

HT High Temperature

IFT Interfacial/Surface Tension

IOS Internal Olefin Sulfonate

$P \quad$ Pressure

$R \quad$ Ideal gas constant

$R_{\mathrm{si}} \quad$ Gas to oil ratio, initial

RCO Representative Crude Oil

S Surfactant

SP Surfactant/Polymer

SRK Soave-Redlich-Kwong

$S^{*} \quad$ Optimal salinity

$T \quad$ Temperature

TDS Total Dissolved Solids

V Volume

$V_{\mathrm{m}} \quad$ Molar volume

WI Winsor I

WII Winsor II

WIII Winsor III

$x \quad$ Molar fraction

$Z \quad$ Compressibility factor

\section{INTRODUCTION}

The actual capacity of oil extraction after applying primary and secondary recovery methods can be roughly estimated to half of the initial oil reservoir content, according to the considered field [1]. The development of tertiary recovery methods - Enhanced Oil Recovery (EOR) - has gained interest especially with the increase of crude oil prices [2]. The chemical EOR (cEOR) technique involves combinations of Alkaline/Surfactant/Polymer (ASP) in which alkalis contribute to decreasing both some of surfactant/clay interactions and water/oil Interfacial Tension (IFT) by generating in situ amphiphilic molecules in case of acid oils, surfactants are used to reduce the water/oil IFT, and the role of the polymer is to improve the sweep efficiency. The main role of an ASP, Surfactant/Polymer (SP) or Surfactant (S) formulation aims at achieving ultra-low water/oil IFT in order to mobilize oil trapped by capillary forces. Optimizing a formulation is a challenging and time-consuming task considering that each potentially eligible reservoir exhibits different conditions such as the oil composition, brine salinity and hardness, pressure, temperature.

Winsor first described the phase behavior for \{brine/ surfactant/oil\} systems [3]. As illustrated on Figure 1, at low salinities, oil is solubilized within micelles in the aqueous phase (Winsor I, also labelled WI). At high salinities, brine is solubilized within micelles in the oil phase (Winsor II, also labelled WII). The transition from Winsor I to Winsor II takes place through an intermediate region, Winsor III (WIII) which corresponds to the coexistence of a middle phase composed of oil, brine and surfactant, with excess brine and oil at the thermodynamic equilibrium. The salinity at which the Winsor III occurs more precisely when the microemulsion solubilizes equal amounts of oil and brine, defines the optimum salinity at which the \{brine/surfactant/ oil) system exhibits its lowest IFT.

While advanced methods have been recently proposed to speed up ASP formulation procedure [4, 5], the HydrophilicLipophilic Deviation (HLD) concept, as proposed by Salager et al. [6], is still the keystone of numerous studies $[1,7]$. At HLD $=0$, the Salager relation (Eq. 1) linearly

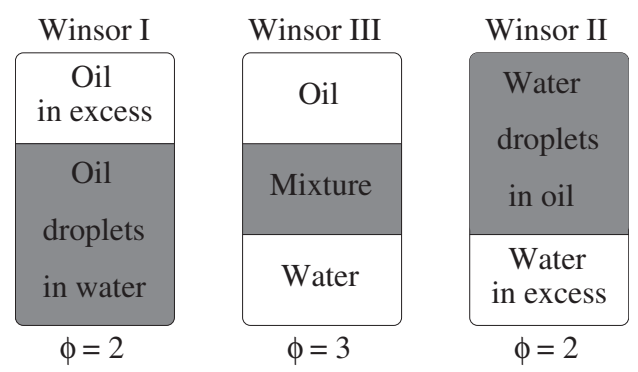

Figure 1

Winsor I $\rightarrow$ III $\rightarrow$ II transition for a brine/formulation/oil system. $\phi$ is the number of phases. Extracted from reference [2]. 
correlates at atmospheric pressure, the optimal salinity $\left(S^{*}\right)-$ the logarithm of the optimum salinity in $\mathrm{g} / \mathrm{L}$ - with some experimentally related features such as the temperature and the EACN of the oil, among others.

$$
S^{*}=K(\mathrm{EACN})+f(A)+\alpha\left(T-T_{\text {ref }}\right)-C c
$$

where $f(A)$ is related to alcohol amount and type, $T_{\text {ref }}$ equals $298.15 \mathrm{~K}, \alpha$ is a temperature coefficient, $C c-$ the characteristic curvature - reflects the tendency of the surfactant to form micelles or reverse micelles $[8,9]$, and $K$ is a parameter related to the formulation chemistry (i.e. chemistry of surfactants, types of salts, TDS - the amount of total dissolved solids - etc.). Investigations of gas dissolution, pressure and temperature effects on the \{brine/formulation/ live oil\} microemulsion have already been performed indicating competing effects [10-13]. Several recent works proposed reviews of these competing effects, for instance when increasing the gas to oil ratio and/or the pressure $[10,13,14]$. Works report that optimal salinity decreases as gas is added to a crude oil at high pressure $[12,15]$ while authors, as Cottin et al. indicated slight increase of $S^{*}[16]$. The temperature affects the microemulsion phase behavior, and increasing $T$ results in increasing $S^{*}$ (Eq. 1) for ionic surfactants while the opposite trend is observed in the case of nonionic surfactants [6, 17]. Since the work early proposed by Nelson [18], various references reported that microemulsion phase behavior is only slightly influenced by the pressure as compared to temperature effect [12, 19-23], and that an increase of $P$ may lead to a Winsor II $\rightarrow$ III $\rightarrow$ I transition, i.e. $S^{*}$ increases. Ghosh and Johns recently proposed an additional term in the Salager's relation to account for pressure effects [14], leading to Equation (2).

$S^{*}=K(\mathrm{EACN})+f(A)+\alpha\left(T-T_{\text {ref }}\right)+\beta\left(P-P_{\text {ref }}\right)-C c$

where $\beta$ is the pressure coefficient and $P_{\text {ref }}$ the reference pressure typically set to atmospheric pressure. It is interesting to note that the $\beta$ coefficient is reported to be about one order of magnitude lower than $\alpha$ [14].

The concept of EACN is commonly used for surfactant formulation design, thereby a single equivalent alkane represents the behavior of a complex hydrocarbon mixture. The determination of EACN for the dead crude oil (EACNdo) and the live crude oil (EACNlo) represents important steps during surfactant formulation design. For instance, EACNdo and EACNlo are key parameters for the determination of the Representative Crude Oil (RCO) - dead oil adjusted with solvents to mimic at lab scale, live oil characteristics at reservoir conditions - [24]. For EACNdo, it can be experimentally performed using test tubes and salinity scans, then matching phase behavior (WIII) of the \{brine/formulation/dead crude oil\} microemulsion with that of the most similar \{brine/formulation $/ n$-alkane\} system. Recently, Wan et al. proposed a review and comparisons of existing approaches usable to experimentally determine the EACN of a dead crude oil [9]. The determination of EACNlo can be performed as described by Oukhemanou et al. [24] but it necessitates time-consuming and hazardous High Pressure (HP) - High Temperature (HT) experiments. In order to reduce the number of such experiments during surfactant formulation, we propose hereafter the development and applications of a relation between EACNdo and EACNlo involving reservoir conditions such as temperature, pressure and the initial gas to oil ratio $\left(R_{\mathrm{si}}\right)$. Such a model would lead to a more rational use of equipments, driving the design of experiments, understanding impacts of some approximations due to $P$ and $T$ conditions and/or the composition of the representative gas. The article is organized as follows: Section 1 presents existing approaches and theoretical details about the model development, in Section 2 we present and discuss case studies for applications of the model, this paper ends with a section which gives our conclusions.

\section{THEORETICAL SECTION}

Several attempts have been done to predict microemulsion phase behavior and to develop correlations in order to reduce the number of experiments. The mole fraction weighted of hydrocarbon EACN (Eq. 3) as proposed by Cayias et al. [25] and Cash et al. [26] has been widely used to estimate the $\mathrm{EACN}_{\text {mix }}$ of heavy hydrocarbon mixtures, at atmospheric pressure [6, 15, 27-29].

$$
\mathrm{EACN}_{\text {mix }}=\sum_{i} x_{i} \mathrm{EACN}_{i}
$$

where, $i$ runs over hydrocarbons in the mixture, and $x_{i}$ and $\mathrm{EACN}_{i}$ are the molar fraction and the EACN of hydrocarbon $i$, respectively.

Several groups recently modeled live oil behavior including reservoir $P$ and $T$ conditions and gas solution [10, 11, 13, 14, 22]. This formulation of Equation (3) has been revisited by Trouillaud et al. who expressed the gas molar fraction in terms of ratio of molar gas and oil volumes, and gas to oil ratio [13]. The application of Equation (3) has been extended to mixtures of oil and gases leading, for instance to an EACN of 10 for methane [22]. Very recently, Marliere et al. have experimentally shown that the optimal salinity (and EACN by extension of Eq. 1) linearly decreases when increasing gas to oil ratio [23]. Thus, it appears promising to account for the volume fractions of gas and oil during any model development. This information being implicit in $R_{\mathrm{si}}$, 
we propose to start from the definition of the gas to oil ratio to extract the gas content of reservoir oil:

$$
R_{\mathrm{si}}=\frac{V_{\mathrm{g}}^{\circ}}{V_{\mathrm{oil}}^{\circ}}=\frac{n_{\mathrm{g}}}{n_{\mathrm{oil}}} \frac{R Z^{\circ} T^{\circ}}{P^{\circ} V_{\mathrm{m}, \mathrm{oil}}^{\circ}}
$$

where $V_{\mathrm{g}}^{\circ}$ and $V_{\text {oil }}^{\circ}$ are volumes of gas and oil in standard conditions $\left(T^{\circ}=288.15 \mathrm{~K}\right.$ and $\left.P^{\circ}=1.01325 \times 10^{5} \mathrm{~Pa}\right)$, respectively. $R$ is the ideal gas constant (8.314 $\left.\mathrm{J} \mathrm{mol}^{-1} \mathrm{~K}^{-1}\right), Z^{\circ}$ the compressibilty factor $\left(Z^{\circ} \simeq 1\right)$ at $T^{\circ}$ and $P^{\circ}, V_{\mathrm{m}, \text { oil }}^{\circ}$ the molar volume of the oil in standard conditions, and $n_{\mathrm{g}}$ and $n_{\text {oil }}$ are the mole numbers for gas and oil, respectively. The molar gas fraction, $x_{\mathrm{g}}$ can be expressed using variables of Equation (4), as follows:

$$
x_{\mathrm{g}}=\frac{1}{1+\frac{R T^{\circ}}{R_{\mathrm{si}} P^{\circ} V_{\mathrm{m}, \text { oil }}^{\circ}}}
$$

The volumetric fraction of gas, $\phi_{\mathrm{g}}$ solved in crude oil at $T$ and $P$ reservoir conditions, can be written as:

$$
\phi_{\mathrm{g}}=\frac{x_{\mathrm{g}} V_{\mathrm{m}, \mathrm{g}}}{x_{\mathrm{g}} V_{\mathrm{m}, \mathrm{g}}+\left(1-x_{\mathrm{g}}\right) V_{\mathrm{m}, \mathrm{oil}}}
$$

where, $V_{\mathrm{m}, \mathrm{g}}$ and $V_{\mathrm{m} \text {,oil }}$ are the molar volume of gas and oil in reservoir conditions, respectively. In Equations (4)-(6), we assume that the dead crude oil can be represented by its EACN (EACNdo) determined experimentally as detailed in references $[23,24]$. The live crude oil EACN can be expressed as a function of EACNdo and gas EACN (EACNg) assuming a linear mixing rule based on volumetric fractions (Eq. 7). The solution gas is modelled on the basis of the detailed synthetic composition mixture containing methane, ethane, proprane, $n$-butane and/or $n$-pentane.

$$
\mathrm{EACNlo}=\left(1-\phi_{\mathrm{g}}\right) \mathrm{EACNdo}+\phi_{\mathrm{g}} \mathrm{EACNg}
$$

where, EACNg equals the sum of $n$-alkane carbon atom numbers (ACN, Alkane Carbon Number) weighted by their respective volumetric fraction, i.e. when solely methane is used as representative gas: EACNg equals 1. If a mixture of light $n$-alkanes is considered to represent the gas, EACNg is calculated assuming a linear mixing rule based on volumetric fractions of mixture components, in reservoir conditions. Using Equations (4)-(7), EACNlo can be estimated using $R_{\mathrm{si}}$ or molar compositions of gases if available, and molar volumes of $n$-alkanes at $P$ and $T$ corresponding to both standard and reservoir conditions. Note that if the detailed oil and gas compositions are available, only Equations (6) and (7) are necessary. In this work, molar volumes were calculated using the Soave-Redlich-Kwong (SRK) [30, 31] Equation of State (EoS) applied with the volume correction proposed by Péneloux et al. [32], as implemented within the Multiflash $^{\mathrm{TM}}$ Software [33]. Indeed, volume translations are required to improve liquid molar volume predicted using cubic EoS [34], noting that the Péneloux correction for alkanes is well documented and its use does not change vapour-liquid equilibrium conditions.

\section{RESULTS AND DISCUSSION}

\subsection{Validation on External Dataset}

Recently, Jang et al. experimentally studied the phase behavior of some live crude oils at HP and HT [22]. In their article, Jang et al. proposed a series of values for dead and live oils including all elements required to feed our model: EACNdo values, gas to oil ratios, oil and gas compositions, and $P$ and $T$ conditions. Table 1 reports an extract of the data published by Jang et al. For each sample and using EACNdo, temperature, pressure and gas to oil ratio values reported in Table 1 to feed Equations (4)-(7), we obtained predicted EACNlo values reported in Table 1. Note that as the detailed oil and gas compositions are available, only Equations (6) and (7) can be used to predict EACNlo. In this latter case, predicted EACNlo values are in good agreement with those (reported in Tab. 1) calculated using $R_{\mathrm{si}}$, with a mean absolute relative deviation of $c a$. 3\%. The observed deviations can be caused by the difference between densities of EACNdos and crude oils (not reported in the article by Jang et al.) in standard conditions, resulting in deviations regarding gas composition estimations (Eq. 5).

EACNlo values proposed by Jang et al. for crude oils $\# \mathrm{~A}, \# \mathrm{~B}, \# \mathrm{C}, \# \mathrm{D}, \# \mathrm{E}$, and $\# \mathrm{H}$ have not been experimentally determined but calculated using Equation (3) and assuming EACN of solution gases as their ACN. A shift of about 2 EACN points is observed between our predicted EACNlo values and those reported by Jang et al. It is also interesting to note that the lowest deviation (1.3 EACN point) between our predictions and Jang et al. values is observed for the crude oil "E" which is reported as the only EACNdo determined by comparison with pure hydrocarbon series, all others were determined by dilution tests.

In cases of samples \#C, \#D1 and \#D3, Jang et al. reported additional EACNlo values of 10.0, 12.9 and 12.7, respectively. Interestingly, EACNlo values estimated with our proposed approach are in good agreement with these latter values determined using dilution curves with varied amounts of toluene. Jang et al. used a linear mixing rule based on molar fractions combined together with a U-shape curve that fits $S^{*}$ evolutions as a function of ACN, the minimum of this $\mathrm{U}$-shape curve is reached for $n$-pentane, the EACN for toluene being unity $\left(\mathrm{EACN}_{\text {toluene }}=1\right)$, and the EACN for methane is 10 , in agreement with previous observations by 
TABLE 1

Summary of some live crude oil properties extracted from reference [22]: ${ }^{a}$ determined using a molar mixing rule, ${ }^{b}$ determined using dilution curves (toluene); ${ }^{c}$ this work

\begin{tabular}{|c|c|c|c|c|c|c|c|c|}
\hline Crude oil & \#A & $\# \mathrm{~B}$ & $\# \mathrm{C}$ & \#D1 & \#D2 & \#D3 & $\# \mathrm{E}$ & $\# \mathrm{H}$ \\
\hline API gravity & 30 & 25 & 25 & 37.3 & 37.3 & 37.3 & 36 & 36.5 \\
\hline EACNdo & 11.4 & 12.4 & 11.3 & 14.0 & 14.0 & 14.0 & 9.9 & 10.0 \\
\hline$T(\mathrm{~K})$ & 383 & 341 & 351 & 363 & 363 & 363 & 295 & 356 \\
\hline$P$ (bar) & 110 & 262 & 159 & 67 & 138 & 172 & 69 & 172 \\
\hline$R_{\mathrm{si}}\left(\mathrm{Sm}^{3} / \mathrm{m}^{3}\right)$ & 50 & 83 & 76 & 39 & 39 & 55 & 18 & 83 \\
\hline $\mathrm{EACNlo}^{a}$ & 7.5 & 6.8 & 6.2 & 10.4 & 10.4 & 8.8 & 8.3 & 5.8 \\
\hline $\mathrm{EACNlo}^{b}$ & - & - & 10.0 & 12.9 & - & 12.7 & - & - \\
\hline EACNlo pred. ${ }^{c}$ & 9.9 & 10.4 & 9.4 & 12.5 & 12.5 & 12.3 & 9.5 & 8.3 \\
\hline
\end{tabular}

Puerto and Reed [15]. It is important to mention that Ghosh and Johns recently advocate not to set the EACN of methane other than unity [14]. Our proposed model is in line with these requirements.

Comparing predicted EACNlo values for \#D1, \#D2, and \#D3 crude oils, our model suggests no or a relatively negligible effect of the pressure (from $\# \mathrm{D} 1$ to $\# \mathrm{D} 2$ ) and a decrease of the EACN is observed when both increasing $R_{\mathrm{si}}$ and/or simplifying the representative gas composition. Additionally, the same group of authors previously investigated crude oil "\#B" at 190 bar in a separate study [35], and reported the same EACNlo value (6.8) suggesting no or negligible effect of pressure on EACNlo.

\subsection{Validation on New Experimental Data}

Table 2 presents some oil properties together with their original reservoir characteristics for a series of live crude oils. These various case studies represent interesting tests for the model as broad ranges of conditions are considered: (i) API gravity index from 25 to 50 , (ii) $R_{\mathrm{si}}$ from 35 to $214 \mathrm{Sm}^{3} / \mathrm{m}^{3}$, (iii) reservoir pressure from 82 to 215 bar, (iv) reservoir temperature from 313 to $393 \mathrm{~K}$, and (v) representative gas compositions from pure methane to mixture of light $n$-alkanes from methane to $n$-pentane. We emphasize that experimental EACN values reported in Table 2 were determined by comparison with salinity scans for a series of $n$-alkanes from $n \mathrm{C}_{8}$ to $n \mathrm{C}_{18}$. Surfactant formulations used to determine EACN are based on mixtures of AOS $(\alpha$-Olefin Sulfonate), IOS (Internal Olefin Sulfonate), AES (Alkyl Ether Sulfate), AGES (Alkyl Glyceryl Ether Sulfonate), and ABS (branched-chain Alkyl Benzene Sulfonate). The formulation is chosen to be thermally stable in the range of considered temperatures. To determine experimental live oil EACN, a Winsor phase diagram was performed by varying the formulation salinity using a high pressure - high temperature sapphire cell. With our apparatus we can separately study the impact of the amount of gas dissolved in the live oil, and the impact of the pressure with pressures up to 500 bar. More details about experimental procedure and apparatus are provided in previous works $[23,24]$. This experimental procedure has been applied to crude oils $\# 01$ to $\# 13$ and so obtained results are presented in Table 2. Gas molar fractions indicated in Table 2 were determined using Equation (6) and the detailed composition of representative gases. Figure 2 illustrates EACNlo values presented in Table 2 through a parity diagram which indicates that data points are not too scattered from both sides of the bisector (predicted EACNlo equals experimental EACNlo). Predicted EACN for live crude oils reasonably agree with experimental values, with an average absolute deviation of about one EACN point. The worst prediction is obtained for fluid \#06 with a deviation of $2.1 \mathrm{EACN}$ points. As a guide, Table 2 presents predictions computed using Equation (3) and assuming EACNg as the ACN of the gas. This latter approach leads to an average absolute deviation of about 3 EACN points with respect to experimental data. Clearly, our proposed approach performs better than the linear molar mixing rule. Very recently, Marliere et al. reported for live crude oil \#01 an experimental uncertainty of 0.2 EACN point on measurements of EACNlo [23]. It is interesting to mention that due to the followed methodology, this uncertainty is related to the $K$ parameter of the Salager Equation (1), and thus to surfactant chemistry. Moreover, the work performed by Marliere et al. shows that the use of the proposed linear volumetric mixing rule is able to mimic variations of EACNlo with $R_{\mathrm{si}}$, which represents an additional validation for our model [23]. 
TABLE 2

Summary of live crude oil properties. For each case study labeled from \#01 to \#13, the API gravity, the experimental EACNdo, reservoir temperature and pressure, the gas to oil ratio, the solution gas composition and EACN, and experimental and predicted EACNlo values are indicated. ${ }^{a}$ this work; ${ }^{b}$ determined using Equation (3) assuming EACNg $=$ ACN of gases

\begin{tabular}{|c|c|c|c|c|c|c|c|c|c|c|c|c|c|}
\hline Crude oil & $\# 01$ & $\# 02$ & $\# 03$ & $\# 04$ & $\# 05$ & $\# 06$ & $\# 07$ & $\# 08$ & $\# 09$ & $\# 10$ & $\# 11$ & $\# 12$ & $\# 13$ \\
\hline API gravity & 27.3 & 30 & 33 & 33 & 38 & 40 & 25.6 & 33 & 35 & 36 & 38 & 38 & 50 \\
\hline EACNdo exp. & 14 & 14 & 13 & 13 & 16 & 12 & 14 & 12 & 15 & 16 & 15 & 15 & 9 \\
\hline$T(\mathrm{~K})$ & 313 & 373 & 383 & 383 & 338 & 355 & 381 & 375 & 348 & 358 & 368 & 368 & 393 \\
\hline$P$ (bar) & 125 & 186 & 155 & 215 & 83 & 190 & 82 & 90 & 140 & 108 & 125 & 143 & 180 \\
\hline$R_{\mathrm{si}}\left(\mathrm{Sm}^{3} / \mathrm{m}^{3}\right)$ & 51 & 48 & 40 & 52 & 54 & 84 & 35 & 53 & 75 & 77 & 69 & 137 & 214 \\
\hline$x_{\text {methane }}$ & 0.359 & 0.345 & 0.291 & 0.348 & 0.400 & 0.446 & 0.261 & 0.216 & 0.290 & 0.289 & 0.294 & 0.418 & 0.339 \\
\hline$x_{\text {ethane }}$ & - & - & - & - & - & - & - & 0.067 & 0.107 & 0.092 & 0.082 & 0.099 & 0.256 \\
\hline$x_{\text {propane }}$ & - & - & - & - & - & - & - & 0.054 & 0.069 & 0.106 & 0.069 & 0.097 & - \\
\hline$x_{n \text {-pentane }}$ & - & - & - & - & - & - & 0.016 & - & - & - & - & - & 0.022 \\
\hline $\mathrm{EACNg}$ & 1.0 & 1.0 & 1.0 & 1.0 & 1.0 & 1.0 & 1.1 & 1.3 & 1.3 & 1.4 & 1.3 & 1.3 & 1.5 \\
\hline EACNlo exp. & 12.0 & 14.0 & 13.0 & 13.0 & 13.5 & 12.0 & 13.0 & 10.0 & 11.0 & 11.5 & 11.5 & 9.0 & 6.5 \\
\hline EACNlo pred. $^{a}$ & 12.5 & 12.5 & 11.9 & 11.5 & 14.1 & 9.9 & 12.6 & 10.4 & 12.5 & 13.0 & 12.5 & 10.8 & 5.7 \\
\hline EACNlo pred. ${ }^{b}$ & 9.3 & 9.5 & 9.5 & 8.8 & 10.0 & 7.1 & 10.5 & 8.5 & 8.7 & 9.0 & 9.0 & 6.7 & 4.4 \\
\hline
\end{tabular}




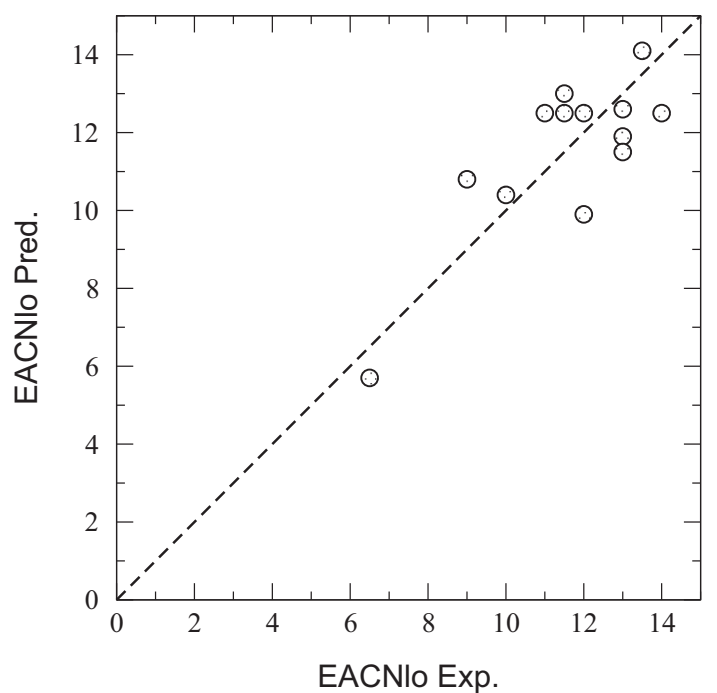

Figure 2

Scatterplot of experimental vs. predicted equivalent alkane carbon number for live crude oils.

\subsection{Investigation of EACNlo Behavior}

We propose to use our model to study the way experimental conditions may affect the EACN of the live crude oil. Table 3 presents EACNlo values calculated for both HP and HT conditions, and for each case study as referenced in Table 2. We propose to define $\alpha^{\mathrm{EACN}}$ and $\beta^{\mathrm{EACN}}$ coefficients temperature and pressure dependence of the EACNlo, respectively - as follows:

$$
\begin{aligned}
& \alpha^{\mathrm{EACN}}=\left(\frac{\Delta(\mathrm{EACNlo})}{\Delta T}\right)_{P} \\
& \beta^{\mathrm{EACN}}=\left(\frac{\Delta(\mathrm{EACNlo})}{\Delta P}\right)_{T}
\end{aligned}
$$

where $\alpha^{\mathrm{EACN}}$ is defined as the shift of live oil EACN resulting from an increase of $1 \mathrm{~K}$ at a fixed $P$, and $\beta^{\mathrm{EACN}}$ is defined as the shift of live oil EACN resulting from an increase of 1 bar at a fixed $T$. For all studied crude oils, the model returns decreasing EACN values with a temperature increase of $\Delta T=100 \mathrm{~K}$ (from $T$ to $T+\Delta T$ ). Our results show that the $\alpha^{\mathrm{EACN}}$ coefficient is function to pressure. For instance, we observed average $\alpha^{\mathrm{EACN}}$ coefficient values of $5 \times 10^{-3}$ and $3 \times 10^{-3} \mathrm{EACN} \mathrm{K}^{-1}$ at 200 and 500 bar, respectively. Figure $3 \mathrm{a}$ exhibits that the gas volumetric fraction in live crude oils $\left(\phi_{\mathrm{g}}\right)$ and $\alpha^{\mathrm{EACN}}$ are correlated.

For all cases, the model returns small increases of EACN values for $\Delta P=300 \mathrm{bar}$ (from $P 1=200$ bar to $P 2=500 \mathrm{bar}$ ). We observe that $\beta^{\mathrm{EACN}}$ is roughly one order of magnitude lower than $\alpha^{\mathrm{EACN}}$ coefficient value, indicating a more

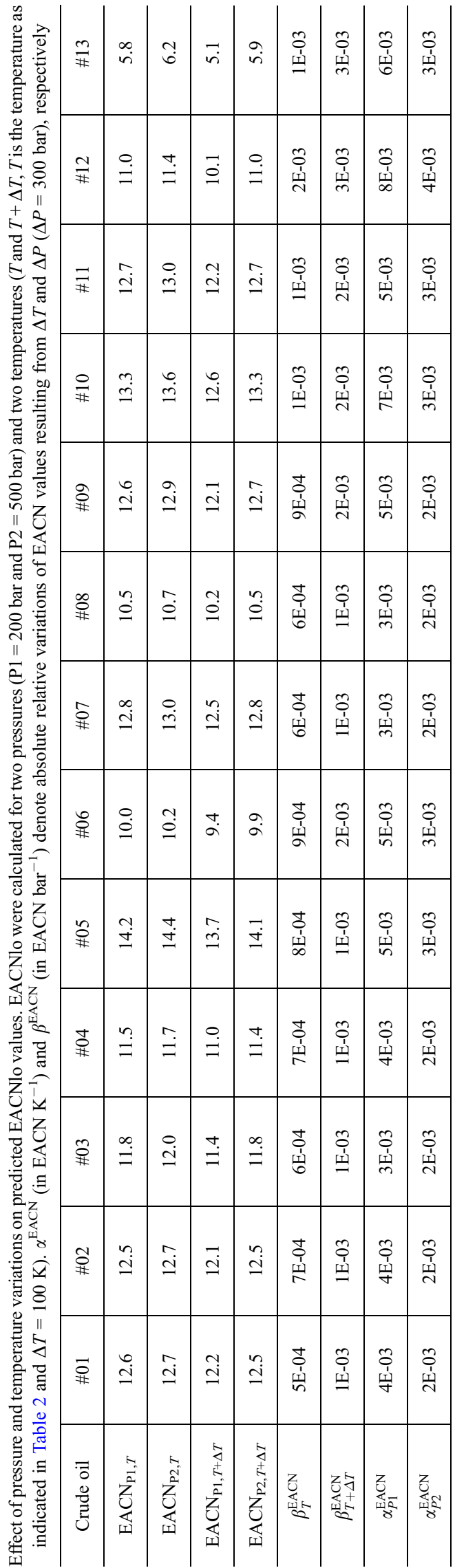



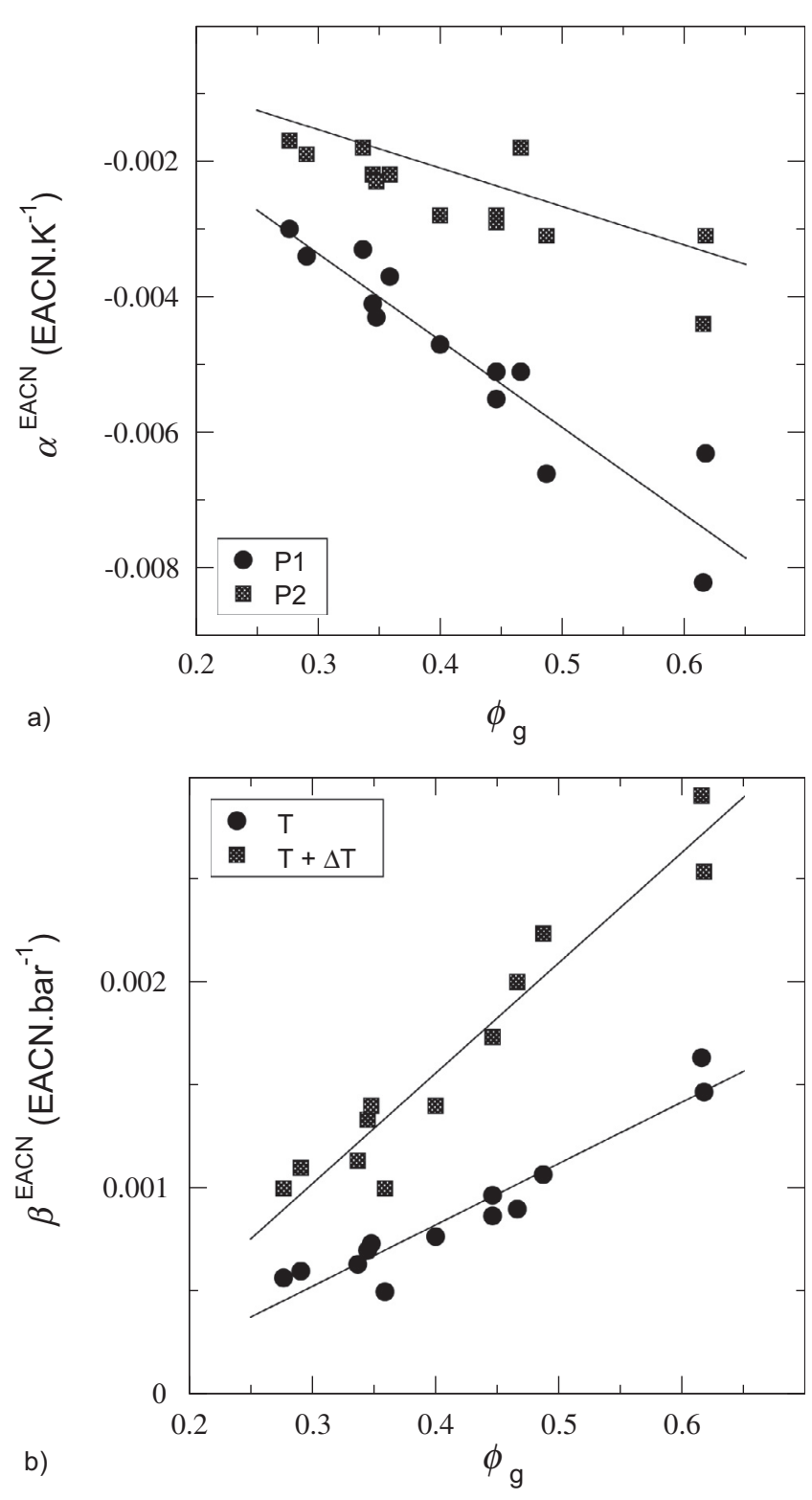

Figure 3

Highlighting of correlations between the gas volumetric fraction in live crude oils and a) $\alpha^{\mathrm{EACN}}$ coefficient and b) $\beta^{\mathrm{EACN}}$ coefficient. $P 1, P 2$, and $\Delta T$ values are indicated in Table 3 .

pronounced effect of temperature as compared to pressure. Our data shows that the $\beta^{\mathrm{EACN}}$ coefficient is related to the temperature. For instance, we observed average $\beta^{\mathrm{EACN}}$ values of $9 \times 10^{-4}$ and $2 \times 10^{-3}$ EACN bar $^{-1}$ at $T$ and $T+\Delta T$ (with $\Delta T=100 \mathrm{~K}$ ), respectively. Moreover, Figure $3 \mathrm{~b}$ reveals that the gas volumetric fraction in live crude oils and $\beta^{\mathrm{EACN}}$ are correlated. $\alpha^{\mathrm{EACN}}$ and $\beta^{\mathrm{EACN}}$ coefficients behave as follows: (i) when $P$ increases $\alpha^{\text {EACN }}$ absolute value decreases, and (ii) when $T$ increases $\beta^{\mathrm{EACN}}$ value increases.

We investigated the impact of the representative gas composition on EACNlo values, e.g. the consideration of pure methane replacing the mixture of light $n$-alkanes. Thus, we studied such a change for live crude oils \#07 to \#13 in Table 2, noting that these mixtures are mainly composed of methane originally. For $P$ and $T$ conditions reported in Table 2, all $\left\{\right.$ EACNdo $\left.+\mathrm{CH}_{4}\right\}$ systems are biphasic, hence to overcome this problem the pressure has been artificially increased in order to reach the monophasic zone of the phase diagram, and Equation (7) was corrected substracting $\beta_{T}^{\mathrm{EACN}} \times \Delta P$. For live crude oils $\# 07$ to $\# 13$, we observed that replacing the gas mixture by pure $\mathrm{CH}_{4}$, a mean EACN increase of 0.3 EACN points is calculated. This EACN increase is to be compared with the uncertainty ( $c a .0 .2$ EACN point) associated to experimental measurements of EACN [23], the model returns a mean impact of gas compositions (without changing the amount of gas solution in the live oil) on EACNlo values within the experimental uncertainty. Our model can be used to indicate whether for a case study pure methane could be used to replace a complex representative gas composition, thereby simplifying experimental campaigns and cost.

\section{CONCLUSIONS AND PERSPECTIVES}

In the context of enhanced oil recovery methods, the cEOR technique implies the optimization of ASP formulations to mobilize oil trapped by capillary forces. We have proposed the development of a model to predict equivalent alkane carbon number of live crude oil being an important parameter during the formulation design and also one of the variable of the widely used Salager relation. Our model consists in a linear mixing rule based on volumetric fractions of the EACN of the dead crude oil and the EACN of the representative gas. Volumetric fractions are determined from reservoir $P$ and $T$ conditions, the initial gas to oil ratio, and EoS outputs.

Model's predictions have been compared with some data from the literature and our own set of experimental data, and a reasonable agreement is observed considering uncertainties. The model was then used to perform predictions of EACNlo varying $P$ and $T$ conditions. Model's predictions indicate that EACNlo is function of both temperature and pressure: EACNlo decreases when $T$ increases and to lesser extent EACNlo increases when $P$ increases. Additionally, we have shown that $\alpha^{\mathrm{EACN}}$ and $\beta^{\mathrm{EACN}}$ coefficients temperature and pressure dependence of the EACNlo, respectively - are related to $P$ and $T$, respectively. The model has also been used to quantify the impact of approximating the composition of representative gas by pure methane. 
All these investigations suggest that the widely used linear molar mixing rule, Equation (3) is not so easily extrapolated to live crude oil at HP and HT conditions.

The work presented in this article provides additional knowledge and more precision in EACN predictions as compared to existing methods. The proposed approach represents an interesting step in the speed up of ASP formulation permitting to strongly narrow down the spectrum of possibilities in terms of EACNlo values. This reduction of necessary high-pressure high-temperature experiments to determine EACNlo values saves time and cost during the formulation process, and thus allowed a more rational use of equipments. The proposed model can be used to drive the design of experiments understanding impacts of some approximations due to $P$ and $T$ conditions and/or the composition of the representative gas.

\section{ACKNOWLEDGMENTS}

Authors wish to thank the EOR Alliance, and more precisely Drs Christine Dalmazzone, Aline Delbos, Christophe Féjean, Valentin Guillon, Claire Marlière, Patrick Moreau, Fanny Oukhemanou, Stéphane Renard, and René Tabary for all relevant discussions.

\section{REFERENCES}

1 Lu J., Liyanage P.J., Solairaj S., Adkins S., Arachchilage G.P., Kim D.H., Britton C., Weerasooriya U., Pope G.A. (2014) New surfactant developments for chemical enhanced oil recovery, Journal of Petroleum Science and Engineering 120, 94-101.

2 Creton B., Nieto-Draghi C., Pannacci N. (2012) Prediction of surfactants' properties using multiscale molecular modeling tools: A review, Oil and Gas Science and Technology 67, 6, 969-982.

3 Winsor P.A. (1948) Hydrotropy, solubilisation and related emulsification processes, Transactions of the Faraday Society 44, 376-398.

4 Moreau P., Maldonado A., Oukhemanou F., Creton B. (2013) Application of quantitative structure-property relationship (QSPR) method for chemical EOR surfactant selection, Paper SPE 164091-MS presented at the SPE International Symposium on Oilfield Chemistry, 8-10 April, Woodlands, Texas, USA.

5 Muller C., Maldonado A.G., Varnek A., Creton B. (2015) Prediction of optimal salinities for surfactant formulations using a quantitative structure-property relationships approach, Energy Fuels 29, 7, 4281-4288.

6 Salager J.L., Morgan J.C., Schechter R.S., Wade W.H., Vasquez E. (1979) Optimum formulation of surfactant/water/oil systems for minimum interfacial tension or phase behavior, Society of Petroleum Engineers Journal 19, 02, 107-115.

7 Budhathoki M., Hsu T.-P., Lohateeraparp P., Roberts B.L., Shiau B.-J., Harwell J.H. (2016) Design of an optimal middle phase microemulsion for ultra high saline brine using hydrophilic lipophilic deviation (HLD) method, Colloids and Surfaces A: Physicochemical and Engineering Aspects 488, 36-45.

8 Acosta E.J., Yuan J.Sh., Bhakta A.Sh. (2008) The characteristic curvature of ionic surfactants, Journal of Surfactants and Detergents 11, 2, 145-158.

9 Wan W., Zhao J., Harwell J.H., Shiau B.-J. (2016) Characterization of crude oil equivalent alkane carbon number (EACN) for surfactant flooding design, Journal of Dispersion Science and Technology 37, 2, 280-287.

10 Roshanfekr M., Johns R.T. (2011) Prediction of optimum salinity and solubilization ratio for microemulsion phase behavior with live crude at reservoir pressure, Fluid Phase Equilibria 304, 1-2, 52-60.

11 Roshanfekr M., Johns R.T., Pope G., Delshad M. (2013) Modeling of pressure and solution gas for chemical floods, Society of Petroleum Engineers Journal 18, 03, 428-439.

12 Southwick J.G., Svec Y., Chilek G., Shahin G.T. (2012) Effect of live crude on alkaline/surfactant polymer formulations: implications for final formulation design, Society of Petroleum Engineers Journal 17, 02, 352-361.

13 Trouillaud A., Patacchini L., de Loubens R., Moncorge A. (2014) Simulation of surfactant flooding in the presence of dissolved and free gas accounting for the dynamic effect of pressure and oil composition on microemulsion phase behavior, Paper SPE 169148-MS presented at the SPE Improved Oil Recovery Symposium, 12-16 April, Tulsa, Oklahoma, USA.

14 Ghosh S., Johns R.T. (2014) A new HLD-NAC based EOS approach to predict surfactant-oil-brine phase behavior for live oil at reservoir pressure and temperature, Paper SPE 170927-MS presented at the SPE Annual Technical Conference and Exhibition, 27-29 October, Amsterdam, The Netherlands.

15 Puerto M.C., Reed R.L. (1983) A three-parameter representation of surfactant/oil/brine interaction, Society of Petroleum Engineers Journal 23, 04, 669-682.

16 Cottin C., Morel D.C., Levitt D., Cordelier P.R., Pope G.A. (2012) (Alkali) surfactant gas injection: Attractive laboratory results under the harsh salinity and temperature conditions of middle east carbonates, Paper SPE 161727-MS presented at the Abu Dhabi International Petroleum Exhibition \& Conference, 11-14 November, Abu Dhabi, UAE.

17 Bourrel M., Salager J.L., Schechter R.S., Wade W.H. (1980) A correlation for phase behavior of nonionic surfactants, Journal of Colloid and Interface Science 75, 2, 451-461.

18 Nelson R.C. (1983) The effect of live crude on phase behavior and oil-recovery efficiency of surfactant flooding systems, Society of Petroleum Engineers Journal 23, 03, 501-510.

19 Kahlweit M., Strey R., Firman P., Haase D., Jen J., Schomaecker R. (1988) General patterns of the phase behavior of mixtures of water, nonpolar solvents, amphiphiles, and electrolytes. 1, Langmuir 4, 3, 499-511.

20 Nagao M., Seto H., Takeda T., Kawabata Y. (2001) Effects of temperature and pressure on phase transitions in a ternary microemulsion system, The Journal of Chemical Physics 115, 21, 10036-10044.

21 Sandersen S.B., Stenby E.H., von Solms N. (2012) The effect of pressure on the phase behavior of surfactant systems: An experimental study, Colloids and Surfaces A: Physicochemical and Engineering Aspects 415, 159-166. 
22 Jang S.H., Liyanage P.J., Lu J., Kim D.H., Arachchilage G.W.P.P., Britton C., Weerasooriya U., Pope G.A. (2014) Microemulsion phase behavior measurements using live oils at high temperature and pressure, Paper SPE 169169-MS presented at the SPE Improved Oil Recovery Symposium, 12-16 April, Tulsa, Oklahoma, USA.

23 Marliere C., Creton B., Oukhemanou F., Wartenberg N., Courtaud T., Féjean C., Betoulle S., Defiolle D., Mougin P. (2016) Impact of live crude oil composition on optimal salinity of a surfactant formulation, Paper SPE 179792-MS presented at the SPE EOR Conference at Oil and Gas West Asia, 21-23 March, Muscat, Oman.

24 Oukhemanou F., Courtaud T., Morvan M., Moreau P., Mougin P., Fejean C., Pedel N., Bazin B., Tabary R. (2014) Alkaline surfactant-polymer formulation evaluation in live oil conditions: The impact of temperature, pressure and gas on oil recovery performance, Paper SPE 169130-MS presented at the SPE Improved Oil Recovery Symposium, 12-16 April, Tulsa, Oklahoma, USA.

25 Cayias J.L., Schechter R.S., Wade W.H. (1976) Modeling crude oils for low interfacial tension, Society of Petroleum Engineers Journal 16, 06, 351-357.

26 Cash L., Cayias J.L., Fournier G., Macallister D., Schares T., Schechter R.S., Wade W.H. (1977) The application of low interfacial tension scaling rules to binary hydrocarbon mixtures, Journal of Colloid and Interface Science 59, 1, 39-44.

27 Salager J.L., Bourrel M., Schechter R.S., Wade W.H. (1979) Mixing rules for optimum phase-behavior formulations of surfactant/oil/water systems, Society of Petroleum Engineers Journal 19, 05, 271-278.

28 Bennett K.E., Phelps C.H.K., Davis H.T., Scriven L.E. (1981) Microemulsion phase behavior observations, thermodynamic essentials, mathematical simulation, Society of Petroleum Engineers Journal 21, 06, 747-762.

29 Graciaa A., Fortney L.N., Schechter R.S., Wade W.H., Yiv S. (1982) Criteria for structuring surfactants to maximize solubilization of oil and water: Part 1-commercial nonionics, Society of Petroleum Engineers Journal 22, 05, 743-749.

30 Redlich O., Kwong J.N.S. (1949) On the thermodynamics of solutions. V. An equation of state. Fugacities of gaseous solutions, Chemical Reviews 44, 1, 233-244.

31 Soave G. (1972) Equilibrium constants from a modified Redlich-Kwong equation of state, Chemical Engineering Science 27, 6, 1197-1203.

32 Péneloux A., Rauzy E., Fréze R. (1982) A consistent correction for Redlich-Kwong-Soave volumes, Fluid Phase Equilibria 8, 1, 7-23.

33 Multiflash $^{\mathrm{TM}}$. Version 4.1, Infochem, KBC Advanced Technologies plc, March 2012.

34 Ungerer P., Batut C. (1997) Prédiction des propriétés volumétriques des hydrocarbures par une translation de volume améliorée, Revue de l'Institut Français du Pétrole 52, 6, 609-623.

35 Lu J., Liyanage P.J., Solairaj S., Adkins S., Arachchilage G.P., Kim D.H., Britton C., Weerasooriya U., Pope G.A. (2013) Recent technology developments in surfactants and polymers for enhanced oil recovery, Paper SPE IPTC 16425 presented at the International Petroleum Technology Conference, 26-28 March, Beijing, China.

Manuscript submitted in January 2016

Manuscript accepted in August 2016

Published online in September 2016

Cite this article as: B. Creton and P. Mougin (2016). Equivalent Alkane Carbon Number of Live Crude Oil: A Predictive Model Based on Thermodynamics, Oil Gas Sci. Technol 71, 62. 